University of Nebraska - Lincoln

DigitalCommons@University of Nebraska - Lincoln

2013

\title{
A Data-Based Conservation Planning Tool for Florida Panthers
}

Jennifer L. Murrow

U.S. Geological Survey

Cindy A. Thatcher

U.S. Geological Survey

Frank T. van Manen

U.S. Geological Survey

Joseph D. Clark

University of Tennessee -Knoxville, jclark1@utk.edu

Follow this and additional works at: https://digitalcommons.unl.edu/usgsstaffpub

Murrow, Jennifer L.; Thatcher, Cindy A.; van Manen, Frank T.; and Clark, Joseph D., "A Data-Based Conservation Planning Tool for Florida Panthers" (2013). USGS Staff -- Published Research. 713. https://digitalcommons.unl.edu/usgsstaffpub/713

This Article is brought to you for free and open access by the US Geological Survey at DigitalCommons@University of Nebraska - Lincoln. It has been accepted for inclusion in USGS Staff -- Published Research by an authorized administrator of DigitalCommons@University of Nebraska - Lincoln. 


\title{
A Data-Based Conservation Planning Tool for Florida Panthers
}

\author{
Jennifer L. Murrow • Cindy A. Thatcher • \\ Frank T. van Manen • Joseph D. Clark
}

Received: 3 January 2012 / Accepted: 19 August 2012 /Published online: 9 September 2012

(C) Springer Science+Business Media B.V. (outside the USA) 2012

\begin{abstract}
Habitat loss and fragmentation are the greatest threats to the endangered Florida panther (Puma concolor coryi). We developed a data-based habitat model and userfriendly interface so that land managers can objectively evaluate Florida panther habitat. We used a geographic information system (GIS) and the Mahalanobis distance statistic $\left(D^{2}\right)$ to develop a model based on broad-scale landscape characteristics associated with panther home ranges. Variables in our model were Euclidean distance to natural land cover, road density, distance to major roads, human density, amount of natural land cover, amount of semi-natural land cover, amount of permanent or semipermanent flooded area-open water, and a cost-distance variable. We then developed a Florida Panther Habitat Estimator tool, which automates and replicates the GIS processes used to apply the statistical habitat model. The estimator can be used by persons with moderate GIS skills to quantify effects of land-use changes on panther habitat at local and landscape scales. Example applications of the tool are presented.
\end{abstract}

Keywords Puma concolor coryi $\cdot$ Florida panther · Habitat model $\cdot$ Mahalanobis distance

\section{Introduction}

The Florida panther (Puma concolor coryi), a subspecies of the puma, is one of the rarest mammals in the world and has been listed as endangered since 1967. The panther

J. L. Murrow $\cdot$ C. A. Thatcher · F. T. van Manen · J. D. Clark $(\triangle)$ U.S. Geological Survey, Southern Appalachian Research Branch, University of Tennessee,

274 Ellington Plant Sciences,

Knoxville, TN 37996, USA

e-mail: jclark1@utk.edu population is estimated at $80-100$ adults and subadults [31] occupying $>800,000$ ha of hardwood forest swamps, cypress swamps, sawgrass marshes, and agricultural areas in south Florida [28, 31, 41, 44]. Habitat loss and fragmentation are the greatest threats to the Florida panther. These threats are primarily a result of rapid human population growth and conversion of natural habitats and agriculture to urban land use [23, 44].

The primary objective of the Florida panther recovery plan is to maintain and expand the current population of panthers in south Florida [44]. The authority to address habitat loss is conferred to the US Fish and Wildlife Service (USFWS) through critical habitat designation and Section 7 of the Endangered Species Act. These decisions must be based on the best available science, and the USFWS requires a method to evaluate panther habitat in south Florida that is objective, quantitative, and transparent. Thus, our objectives were to (1) develop a data-based model of panther habitat in south Florida and (2) integrate the model into a habitat evaluation tool that can be used by land managers to evaluate the potential effects of land-use changes on Florida panther habitat.

\section{Study Area}

Our study area consisted of the USFWS Florida Panther Consultation Area and limited adjacent lands [44]. This area was $30,440 \mathrm{~km}^{2}$ in size and consisted of nine counties in south Florida, with Charlotte, Glades, and Palm Beach counties forming the northern boundary (Fig. 1). Publicly owned land accounted for $57.3 \%$ of the study area [16]. The largest public land parcels were Everglades National Park, Big Cypress National Preserve, and several Water Conservation Areas, all located in the southern portion of the Florida peninsula. 
Fig. 1 Study area and composite range of all Florida panthers used in the analysis, expressed as a $95 \%$ fixed kernel, 1995-2005

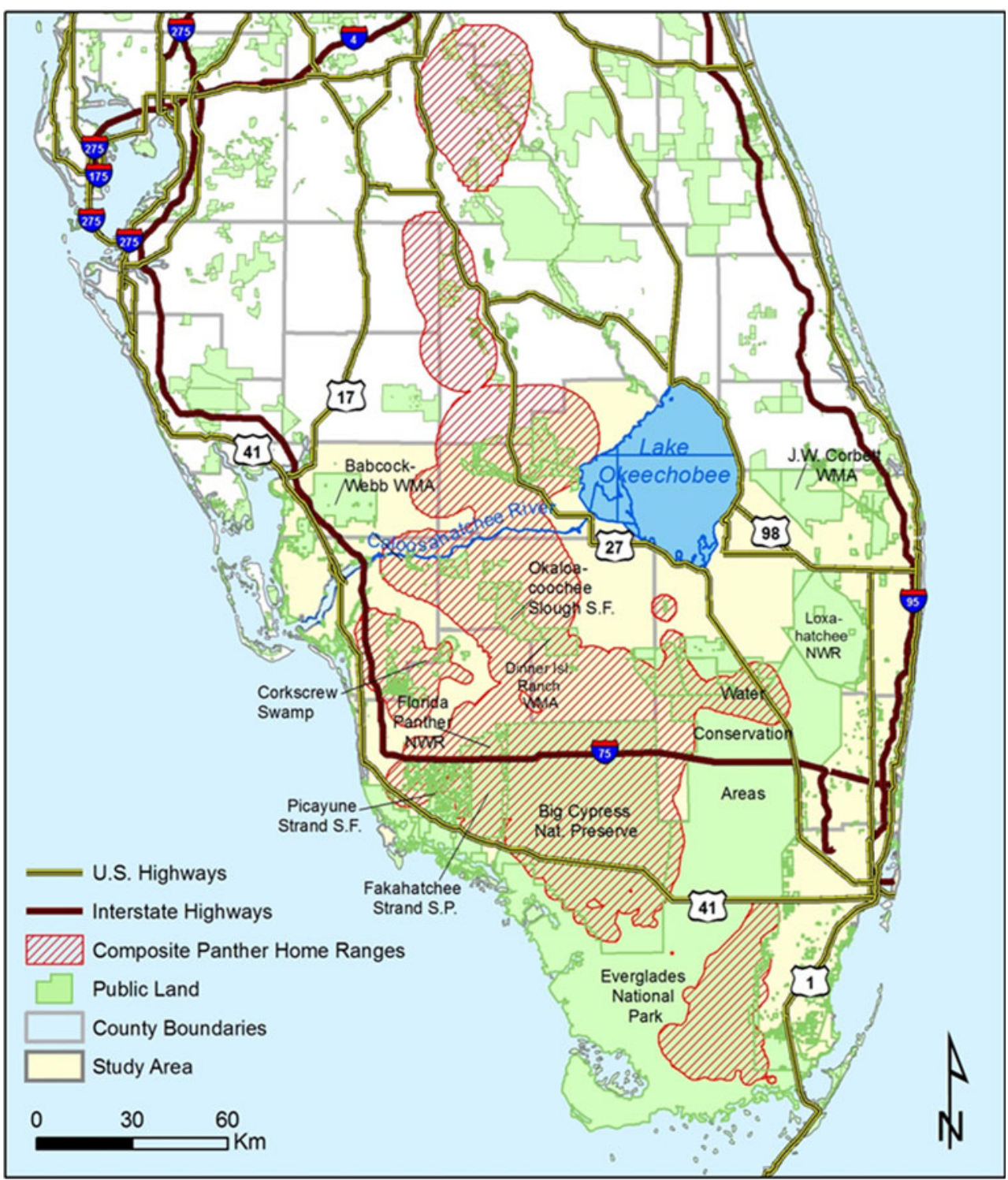

The study area was characterized by relatively flat topography and poorly drained soils resulting in extensive wetlands [10]. Elevations ranged from sea level to $95 \mathrm{~m}$. The climate of southern Florida was tropical, with a summer wet season and a winter dry season [10]. Major vegetation types included pine forests, cypress (Taxodium spp.) and mixed hardwood swamps, hardwood hammocks, cabbage palm (Sabal palmetto) forests, mangroves (Avicennia germinans, Rhizophora mangle), saw palmetto (Serenoa repens) prairies, and herbaceous wetlands such as sawgrass prairies (Cladium mariscus var. jamaicense) [15]. Mean annual rainfall ranged from 114 to $157 \mathrm{~cm}$ [43]. Approximately $14 \%$ of the study area was used for agriculture, including pasture, sugarcane fields, citrus groves, and row crops [15]. About $10 \%$ of the study area was characterized by urban land use, particularly along the Atlantic and Gulf coasts.

\section{Methods}

\subsection{Habitat Model}

Telemetry Data Panther radio-telemetry data formed the basis for our model. Panther telemetry data were collected by the Florida Fish and Wildlife Conservation Commission, the National Park Service, and the University of Tennessee from 1981 to July 2005, and included >76,000 locations from 117 individual panthers [41]. Mean telemetry error for locations collected by all agencies was estimated to be $176 \mathrm{~m}$, with $95 \%$ of locations within $489 \mathrm{~m}$ of the true location [28]. We used a subset ( $n=97$ individuals) of telemetry data from 1995 to June 2005 to maintain concurrency with the 2003 Florida vegetation and land-cover data [15], which provided the basis for a number of variables in the habitat model. 
We excluded data for panthers $<18$ months of age because these animals were usually dependent on their mothers and likely exhibited movement and activity biases [28]. Our telemetry data subset included locations of eight female Texas mountain lions (Puma concolor stanleyana) and their offspring introduced to south Florida in 1995. The frequency of radiolocation data collection per week varied over the period studied, so we standardized the data to include no more than three locations per week for each animal and excluded panthers with $<50$ locations because of possible bias in home range estimation when using the fixed-kernel method [39, 40]. Ninety-seven panthers (56 F, $41 \mathrm{M})$ with 39,488 telemetry locations met the age and sample size requirements.

Panthers were monitored year-round, with an average of three relocations per week collected during daylight hours. We used panther home ranges rather than individual radiolocations as our sampling unit because home ranges are less sensitive to temporal differences in habitat selection, telemetry location error, and autocorrelation than individual radiolocations $[30,36]$. We pooled male and female home ranges because we wanted to assess overall panther habitat and because a habitat estimator based on two different models is not practical for application by land managers. We delineated a home range for each panther by calculating a $95 \%$ probability contour using the fixed-kernel method [45] available in the Animal Movement extension [24] to ArcView $^{\circledR}$ GIS (v.3.2, ESRI ${ }^{\circledR}$, Redlands, CA, USA). For kernel methods, the width of the kernel, or smoothing parameter, can have a strong effect on the home range estimate [25]. We determined the smoothing parameter based on least-squares cross-validation (LSCVh; [46]). Although a newer method using likelihood cross-validation $(\mathrm{CVh})$ generally outperformed LSCVh, differences at larger sample sizes ( $>50$ locations) were less distinct [25]. One of our selection criteria was a minimum of 50 locations per panther so our home ranges likely were not biased because of the method to estimate the smoothing parameter. Also, the testing methods we chose were robust to extremes in home ranges and sample size [29].

Landscape Data We used 2005 US Census Bureau road data and 2003 Florida Fish and Wildlife Conservation Commission land-cover data for model development. These data were previously used to develop a habitat model to assess habitat north of the Caloosahatchee River for Florida panthers [41]; however, that model was at a coarser resolution than we needed for the current study and we wanted to explore additional predictor variables. Variables for that earlier model were (1) amount of semi-natural land cover, (2) amount of natural land cover, (3) patch density of natural land cover, (4) Euclidean distance to nearest natural land cover, (5) Euclidean distance to nearest forest, and (6)
Euclidean distance to nearest agriculture. For the current model, we also evaluated (7) human population density, (8) road density, (9) Euclidean distance to major roads (interstates and US Highways), (10) amount of permanent or semi-permanent flooded area-open water, and (11) leastcost distance to core panther range. We set the resolution of all 11 variables to $30 \mathrm{~m}(30-\times 30-\mathrm{m}$ pixels $)$. Except for Euclidean and cost-distance variables, we derived each landscape variable based on neighborhood analyses (FOCALMEAN operation in ArcMap ${ }^{\mathrm{TM}}$ ) using a circular moving window with a 3,280-m radius, a scale approximately equivalent to the mean daily movement rate of male and female panthers. That is, we used a base layer (e.g., land cover) and created new GIS grids for the model variables (e.g., amount of natural landcover) by assigning to each pixel the averaged or summed values of pixels in the base layer within a 3,280-m radius.

We considered using individual land-cover types for our model, but the distribution of those individual types differed across the study area and between areas where panthers did and did not occur. Our concern was that use of many landcover types would over-parameterize the model and be specific to presently occupied areas but would not allow identification of unoccupied areas. For example, wetland prairies were common in the southern portion of our study area but rare in the northern portion. Consequently, a habitat model with wetland prairie as a variable would predict poorer habitat in the north, which we did not deem reasonable. Instead, we consolidated land-cover types into three classes to avoid that problem while still providing sufficient specificity to be discriminative: natural (forests, grasslands, shrublands, cypress swamps), semi-natural (bare soil, improved and unimproved pasture, exotic vegetation), and other (urban, agricultural row crops, open water). We then calculated the amount of natural land cover for each pixel by summing the number of pixels with natural land cover within the 3,280-m radius analysis window. We repeated this process to calculate the amount of semi-natural land cover. We also developed variables based on patch density of natural land cover to quantify spatial patterns of landscape heterogeneity and fragmentation and to represent different configurations of land-cover type. We calculated the density of natural land-cover patches in the study area with Program FRAGSTATS 3.1 [34], with high patch densities indicating greater habitat fragmentation.

To account for Florida panther use associated with proximity to a given land-cover type, we derived a continuous map layer based on Euclidean distance to the nearest pixel classified as natural land cover. We developed two other map layers by similarly calculating the Euclidean distance to the nearest pixel classified as forest and agriculture, respectively. Addition of Euclidean distance variables provided a greater level of detail by capturing the land-cover conditions 
at individual 30-m pixels, rather than the average conditions within a larger area.

We included spatial data on human population density and roads in the model as a measure of anthropogenic influences on the landscape. Human disturbance may increase habitat fragmentation, create impediments to panther movement, and increase the risks to panthers from vehicular mortality and poaching [6]. We calculated average human population density within the $3,280-\mathrm{m}$ radius moving window using block-level US Census Bureau data. We calculated road density as the total length of roads within the 3,280-m radius moving window using 2000 US Census Bureau TIGER Line data. We excluded unpaved roads and roads accessible only by fourwheel-drive vehicles because they usually have little traffic. Because wide, heavily trafficked roads can act as barriers to panther movement [11, 17], we developed a second road variable based on Euclidean distance from interstate and US highways only.

Areas that are perennially inundated are less able to support white-tailed deer (Odocoileus virginianus), an important source of prey for Florida panthers $[6,14]$. Therefore, we developed a map layer representing flood conditions based on National Wetlands Inventory (NWI) data [8]. First, we used the water regime classification in the NWI attribute tables to group wetlands data into three categories: (1) permanently or semi-permanently flooded or open water, (2) seasonally or temporarily flooded, and (3) uplands or intermittently flooded. We then calculated the average proportion of the area within the $3,280-\mathrm{m}$ radius moving window that was permanently or semi-permanently flooded or had open water.

Finally, we included a variable in the model to measure the relative importance of land parcels based on their proximity to the core of panther range. Parcels proximal to current panther range are likely more important for metapopulation function and viability than a distant parcel [18]. We developed a cost-distance grid to quantify the difference between contiguous habitat patches within the current Florida panther distribution and isolated patches farther removed from the current distribution. We first determined the centroid of all panther home ranges. We used one centroid instead of several centroids of smaller subpopulations of panthers on the landscape because the distribution of the population was fairly contiguous and could be adequately characterized by one central value. Next, we developed a resistance grid in which we assigned natural land cover a resistance value of 0 and all other land-cover types a value of 1 . We assumed that it was easiest for panthers to move through natural land-cover types and more difficult to move through non- or semi-natural land-cover types. Finally, we used a resistance surface [1] derived from land cover with the cost-distance algorithm in ArcMap ${ }^{\mathrm{TM}}$ to calculate least- cost distances for all pixels within the study region to the centroid of panther home ranges.

Model Development We used Mahalanobis distance (hereafter, $D^{2}$ ) as our habitat modeling technique [5]. $D^{2}$ is a multivariate statistic that represents a measure of dissimilarity [38] and has been used to assess habitat for a wide range of plant and animal species [2, 5, 7, 13, 20, 32, 42]. This technique predicts habitat suitability based on location data and GIS data layers using the following equation:

$D^{2}=(\underline{x}-\underline{\widehat{u}})^{\mathrm{T}} S^{-1}(\underline{x}-\underline{\widehat{u}})$,

where $\underline{x}$ is a vector of landscape characteristics in the GIS grid, $\underline{\hat{u}}$ is the mean vector of landscape characteristics associated with panther home ranges (i.e., target data), and $S^{-1}$ is the inverse of the variance-covariance matrix calculated from the home ranges [38]. Use of $S^{-1}$ effectively standardizes the different habitat variables and eliminates effects of correlation among them. In our case, the mean vector of landscape variables within each panther home range formed the target with which the remainder of the study area was compared. The $D^{2}$ statistic for each pixel provides a unit-less index of similarity to the multivariate landscape conditions associated with the target data [33].

Mahalanobis distance is well-suited for modeling a secretive, wide-ranging animal such as the Florida panther because it requires only presence data for input, rather than both presence and absence data. This statistical technique avoids the potential difficulties involved in classifying available habitats as unused as is required for many other techniques (e.g., logistic regression) $[21,37]$. Because $D^{2}$ scores can range from 0 to infinity, we recoded the $D^{2}$ scores into ten categories based on equal percentiles. For example, $D^{2}$ values for the lowest tenth percentile of the study area were categorized as 900 to 1,000 , the next tenth percentile as 800 to 900 , and so on. We refer to these recoded $D^{2}$ scores as habitat index values and used 1,000 as the upper limit because it eliminated the need for floating point GIS grids. Habitat index values closer to 1,000 indicate greater similarity to the landscape conditions defined by the panther home ranges, thus corresponding to more favorable landscape conditions.

Model Selection and Testing We developed several habitat models based on different combinations of landscape variables and used quantitative and qualitative criteria to select the final model [41]. For example, we examined means and standard deviations for each variable within panther home ranges and compared them with values based on the overall study area. If the coefficient of variation for a particular variable was low within panther home ranges compared with the study area, we assumed habitat selection occurred and that variable was potentially important. Similarly, 
differing means between panther home ranges and the study area could be indicative of variable importance. Finally, we did not always use strictly quantitative evaluation procedures for evaluating variables in the final model. In a few cases, the quantitative tests produced results that were inconsistent with the effect that we visually observed when we applied the model to the landscape. For example, inclusion of the amount of permanent or semi-permanent flooded area-open water did not improve performance in a quantitative way but was successful in identifying large stormwater treatment areas that clearly did not represent panther habitat.

After constructing the final $D^{2}$ model, we used a principal components analysis to assess relationships among variables by calculating the eigenvalues for each eigenvector based on the correlation matrix and identifying significant components of the model $[27,35]$. To determine the number of components to interpret from the principal components analysis, we evaluated any components that explained $>10 \%$ of the total variance. We also used the broken-stick method [19], which is based on the assumption that, if total variance (i.e., the sum of the eigenvalues) is divided randomly among the various components, the expected distribution of eigenvalues will follow the broken-stick distribution [26]. Observed eigenvalues are considered interpretable if they exceed eigenvalues generated by the broken-stick distribution.

We used three different techniques to test the $D^{2}$ model: (1) cumulative frequency graphs of panther home ranges and random home ranges, (2) correct classification of habitat as suitable for panther home ranges based on tenfold validation, and (3) calculation of the Boyce index based on tenfold cross-validation [3, 22]. Although calculation of $D^{2}$ does not require delineation of available habitat, we had to define a study area boundary to calculate the expected frequency of home ranges based on the area of each habitat index class. We used the USFWS Florida Panther Consultation Area as the spatial extent for testing because that represents the area where the model would be applied.

To generate the cumulative frequency distribution for the panther home ranges, we first calculated the mean habitat index value for each panther home range and plotted the cumulative frequency of those values. We then generated a set of test home ranges, equal in size and number to the average home ranges of our sample, randomly placed them throughout the study area, and calculated their mean habitat index values. We plotted the cumulative frequencies of those home ranges as well, allowing comparisons between the panther and random home ranges. We then tested for differences between cumulative frequency distributions of $D^{2}$ values from the set of random home ranges and the panther home ranges using a Kolmogorov-Smirnov test, which is robust to extremes in home range and sample sizes [29]. Finally, we determined the index value at which the distance between the two cumulative frequency distributions was greatest, thereby identifying the point below which the probability of containing the greatest percentage of known panther home ranges in the smallest percentage of the study area was greatest [4]. Although habitat suitability represents a continuum, this binary reclassification enabled us to characterize individual pixels as panther habitat or non-habitat.

We performed a tenfold cross-validation to determine correct classification rates and identify any outliers in the data. We then used that tenfold cross-validation to calculate the Boyce index, which is based on the ratio of the number of observed home ranges within a particular range of habitat index values predicted by the model and an area-adjusted expected frequency of home ranges (i.e., representing a null model) within that same range of habitat index values [3, 22]. We calculated those ratios for five classes (bins) of the habitat index values. The bin values were independently established by equally dividing the random home range values into five equal parts. A Boyce index of 0 indicates lower use than expected, whereas a ratio of 1.0 indicates use in proportion to availability. Ratios greater than 1.0 represent habitats for which selection takes place. If the habitat model is successful at predicting panther habitat, the Boyce index would have a low frequency at lower values and a high frequency at higher values, or would have an increasing value across binned categories (least to greatest). Spearman-rank correlations $\left(r_{\mathrm{s}}\right)$ between bin ranks and area-adjusted frequencies for model sets $>0.7$ indicate a strong relationship [3].

\subsection{Florida Panther Habitat Estimator}

Based on the final $D^{2}$ model, we developed a habitat estimator and user-friendly interface to recalculate $D^{2}$ when landscape changes occur (Fig. 2). The estimator was designed for ArcMap ${ }^{\mathrm{TM}}$ software to evaluate habitat within the Florida Panther Consultation Area. The Florida Panther Habitat Estimator tool consisted of two main functions: estimation of the cumulative habitat index value within a user-defined polygon and estimation of changes in habitat index values as a result of changes to the landscape. The estimator automates and replicates the GIS processes to recalculate $D^{2}$ and habitat index values based on new landscape data, but it does not re-parameterize the mean habitat vectors or covariate matrix. The estimator is executed from a graphical user interface in the ArcToolbox module of Arc$\mathrm{Map}^{\mathrm{TM}}$ and can be operated by users with moderate knowledge of GIS software. We used Python ${ }^{\mathrm{TM}}$ scripting language to enable the estimator to be used with ESRI ${ }^{\circledR}$ ArcMap $^{\mathrm{TM}}$ software. We chose Python ${ }^{\mathrm{TM}}$ scripting language, rather than 
Fig. 2 Example input screen (top) and output data (bottom) illustrating the capabilities of the Florida Panther Habitat Estimator to evaluate effects of land-use changes on panther habitat in south Florida

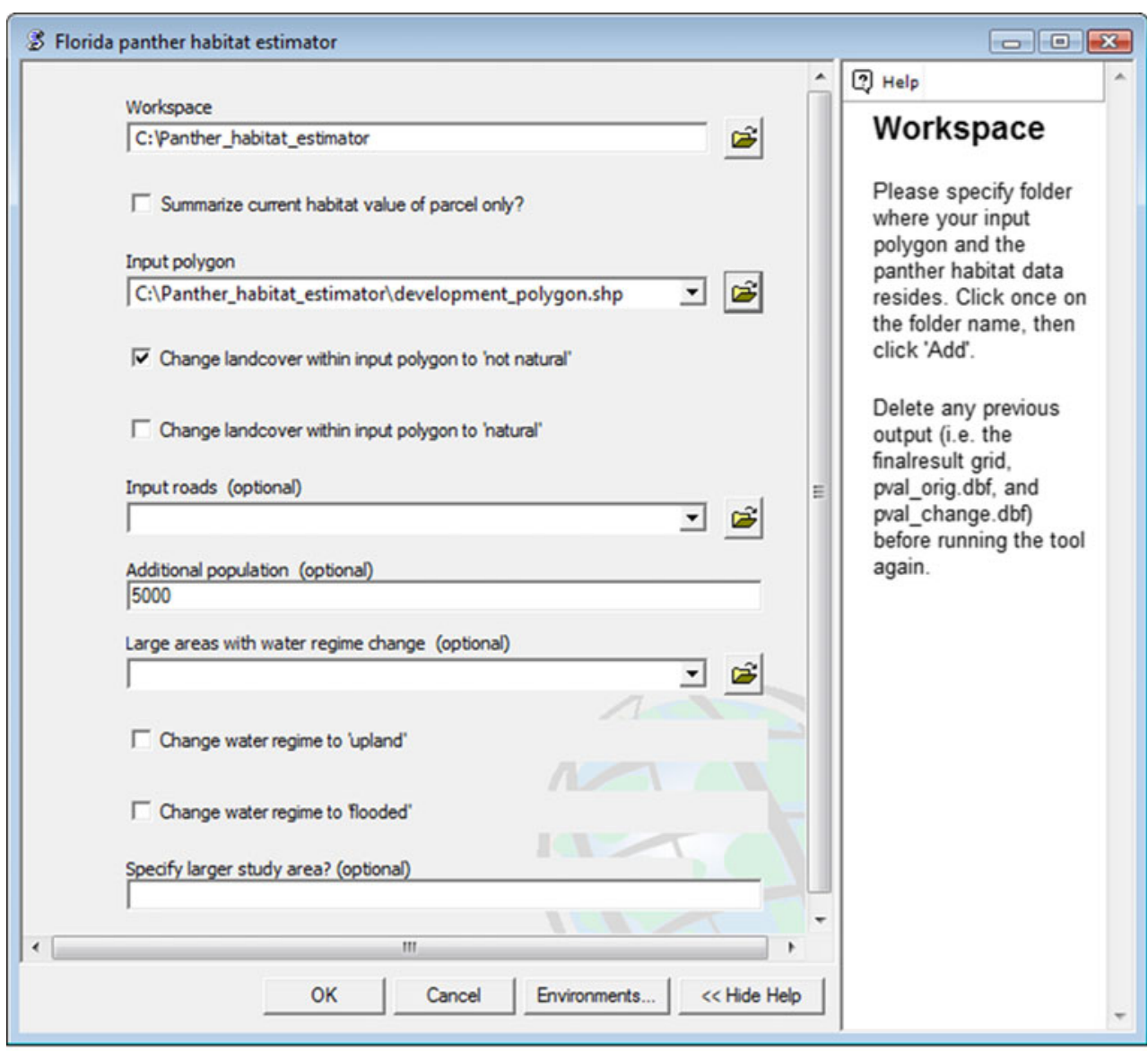

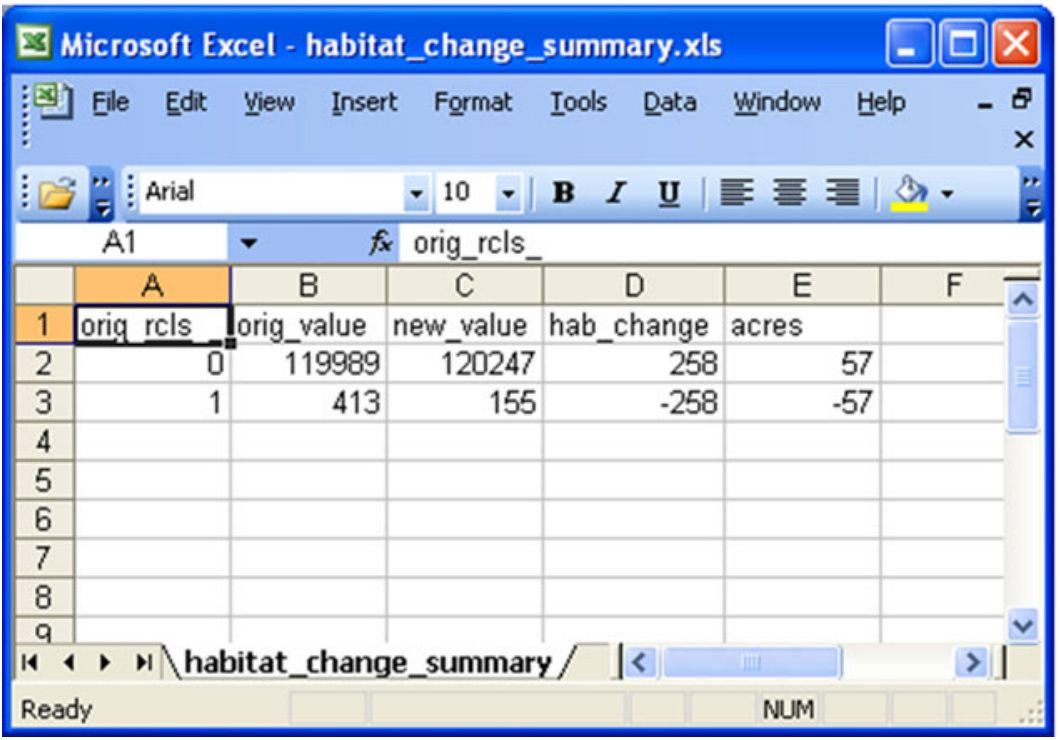

VBScript or Jscript, because it is an open-source compliant, platform independent (i.e., it can operate on UNIX, Linux, or Windows platforms) [12] programming language with easily readable code.

The Florida Panther Habitat Estimator was designed to tally the number of panther habitat units (i.e., the sum of habitat index values for all pixels within a user-defined analysis area) within a user-specified polygon prior to any land-use changes. Such changes could include the conversion of natural land-cover types to non-natural (e.g., row crops) within a polygon, the addition of roads (i.e., changing the road density data layer), the addition of human residents (i.e., changing the human population density data layer), and land-to-water conversion (i.e., for stormwater treatment, 
Table 1 Eigenvalues and proportion of variance explained by eight principal components for a Mahalanobis distance model to evaluate Florida panther habitat within the US Fish and Wildlife Service Florida Panther Consultation Area, south Florida, 1995-2005

\begin{tabular}{llll}
\hline $\begin{array}{l}\text { Principal } \\
\text { component vector }\end{array}$ & Eigenvalue & $\begin{array}{l}\text { Proportion } \\
\text { of variance }\end{array}$ & $\begin{array}{l}\text { Broken-stick } \\
\text { model proportion } \\
\text { of variance }\end{array}$ \\
\hline 1 & 3.2175 & 0.4022 & 0.3397 \\
2 & 1.5224 & 0.1903 & 0.2147 \\
3 & 1.1806 & 0.1476 & 0.1522 \\
4 & 0.7671 & 0.0959 & 0.1106 \\
5 & 0.5723 & 0.0715 & 0.0793 \\
6 & 0.5161 & 0.0645 & 0.0543 \\
7 & 0.1299 & 0.0162 & 0.0335 \\
8 & 0.0942 & 0.0118 & 0.0156 \\
\hline
\end{tabular}

${ }^{\text {a }}$ Proportions of any model with eight variables [19, 26]

agriculture, and other purposes). Similarly, habitat restoration can be simulated by converting non-natural land-cover types to natural, removing roads, and so forth. The result would be a quantitative estimate of gain or loss in panther habitat units.

To simulate the effects of a potential land-use change, the user provides a polygon (any shape or size) of the proposed evaluation site as an ArcMap ${ }^{\mathrm{TM}}$ shapefile. The user specifies the land-cover type to be assigned to that polygon (nonnatural, semi-natural, or natural), new road data, changes in human population size, and changes in flooding status of the polygon. The default setting of the estimator is to sum changes in habitat index values within an area with a radius, or buffer, of 3,280 m surrounding the polygon being evaluated. We restricted the analysis area because the computing time to recalculate the variables for the entire study area is lengthy. Once the data are entered, the model recalculates percent natural land cover and distance to natural land cover and the cost-distance variable likewise is recalculated based on changes in natural land cover. Road density and human density data layers are recalculated as is the percent permanent or semi-permanent flooded area-open water layer. The estimator then recalculates the habitat grid using the original multipliers derived from the Mahalanobis distance calculations. The resulting map layer contains the new habitat index values within the user-defined polygon and surrounding area. Finally, an Excel file is created that specifies the quantitative change in panther habitat index value units within the buffer and the area of Florida panther habitat lost or gained based on classifications above or below the threshold value as specified by the cumulative distribution function.

\subsection{Simulation Scenario Examples}

We evaluated the performance of the estimator tool to assess landscape changes based on two different scenarios. We first simulated a hypothetical 1,820-ha (4,500-ac) habitat alteration located in the western portion of panther range (Lee County). This simulation involved conversion of natural land cover to agricultural row crops (i.e., non-natural land cover), which would contain no additional roads or people, thus only impacting land use. We repeated this simulation by adding 5,000 people to the polygon that was converted to non-natural land cover, thus representing a housing development (Fig. 2). In the second scenario, we evaluated the potential impact of an alteration to a habitat linkage site located south of Okaloacoochee Slough State Forest using a hypothetical linear conversion of 169 ha of natural to non-natural land cover including roads and 240 residents. We evaluated changes in habitat by defining a buffer area of $18 \mathrm{~km}$ beyond the development boundaries.

\section{Results}

\subsection{Habitat Model}

Mean home range sizes for males $(n=41)$, females $(n=56)$, and both sexes combined was $677 \mathrm{~km}^{2}(\mathrm{SD}=780), 212 \mathrm{~km}^{2}$ $(\mathrm{SD}=146)$, and $409 \mathrm{~km}^{2}(\mathrm{SD}=565)$, respectively. Patch

Table 2 Habitat model variables and corresponding eigenvectors for a Mahalanobis distance model to evaluate Florida panther habitat within the US Fish and Wildlife Service Florida Panther Consultation Area, south Florida, 1995-2005

\begin{tabular}{lccccrrrr}
\hline Variable & \multicolumn{3}{l}{ Eigenvectors of principal components (PC) } & & & \\
\cline { 2 - 9 } & PC1 & PC2 & PC3 & PC4 & PC5 & PC6 & PC7 & PC8 \\
\hline Road density & 0.232 & -0.584 & -0.050 & -0.045 & 0.662 & 0.292 & -0.165 & -0.224 \\
Population density & 0.201 & -0.476 & 0.025 & 0.766 & -0.337 & -0.115 & 0.128 & 0.051 \\
Distance to water & 0.101 & 0.205 & 0.787 & 0.138 & -0.038 & 0.550 & 0.044 & -0.060 \\
Cost distance & 0.468 & 0.136 & 0.237 & -0.101 & 0.110 & -0.528 & 0.355 & -0.528 \\
Percent natural & -0.439 & 0.052 & 0.227 & 0.263 & 0.575 & -0.283 & 0.394 & 0.344 \\
Distance to natural & 0.502 & 0.080 & 0.219 & -0.040 & 0.127 & -0.314 & -0.479 & 0.590 \\
Percent semi-natural & 0.468 & 0.136 & -0.335 & -0.080 & 0.047 & 0.357 & 0.610 & 0.377 \\
Distance to road & 0.113 & 0.587 & -0.332 & 0.552 & 0.293 & 0.113 & -0.270 & -0.236 \\
\hline
\end{tabular}


density, distance to forest, and distance to agriculture had similar means or similar coefficients of variation between the panther home ranges and the study area, and we excluded those variables from further analyses. We used Euclidean distance to natural land cover, road density, distance to major roads, human density, amount of natural land cover, amount of semi-natural land cover, amount of permanent or semi-permanent flooded area-open water, and the cost-distance variable in the final Mahalanobis distance model (Fig. 3). The principal components analysis indicated the first three components each explained $>10 \%$ of model variation, but the second and third components were just below the broken-stick eigenvalues (Table 1). Model variables with the strongest correlation in the first principal component were distance to natural cover, cost distance, percent semi-natural cover, and percent natural cover (Table 2). Although the second component did not meet the broken-stick criterion, it explained $19 \%$ of model variation, and distance to road and road density were heavily weighted.

The cumulative frequency distribution of mean $D^{2}$ values for panther home ranges was distinctly different than that based on randomly placed home ranges $(D=0.598, P<$ 0.001; Fig. 4). The greatest distance between the distributions of panther and random home ranges occurred at a habitat index value of 360 . Tenfold cross-validation of the final model indicated no outlier home ranges, with consistently high correct classification rates $(89.5-100 \%)$.

Fig. 3 Habitat index values used to identify potential Florida panther habitat in southern Florida based on circa 2003 landscape conditions

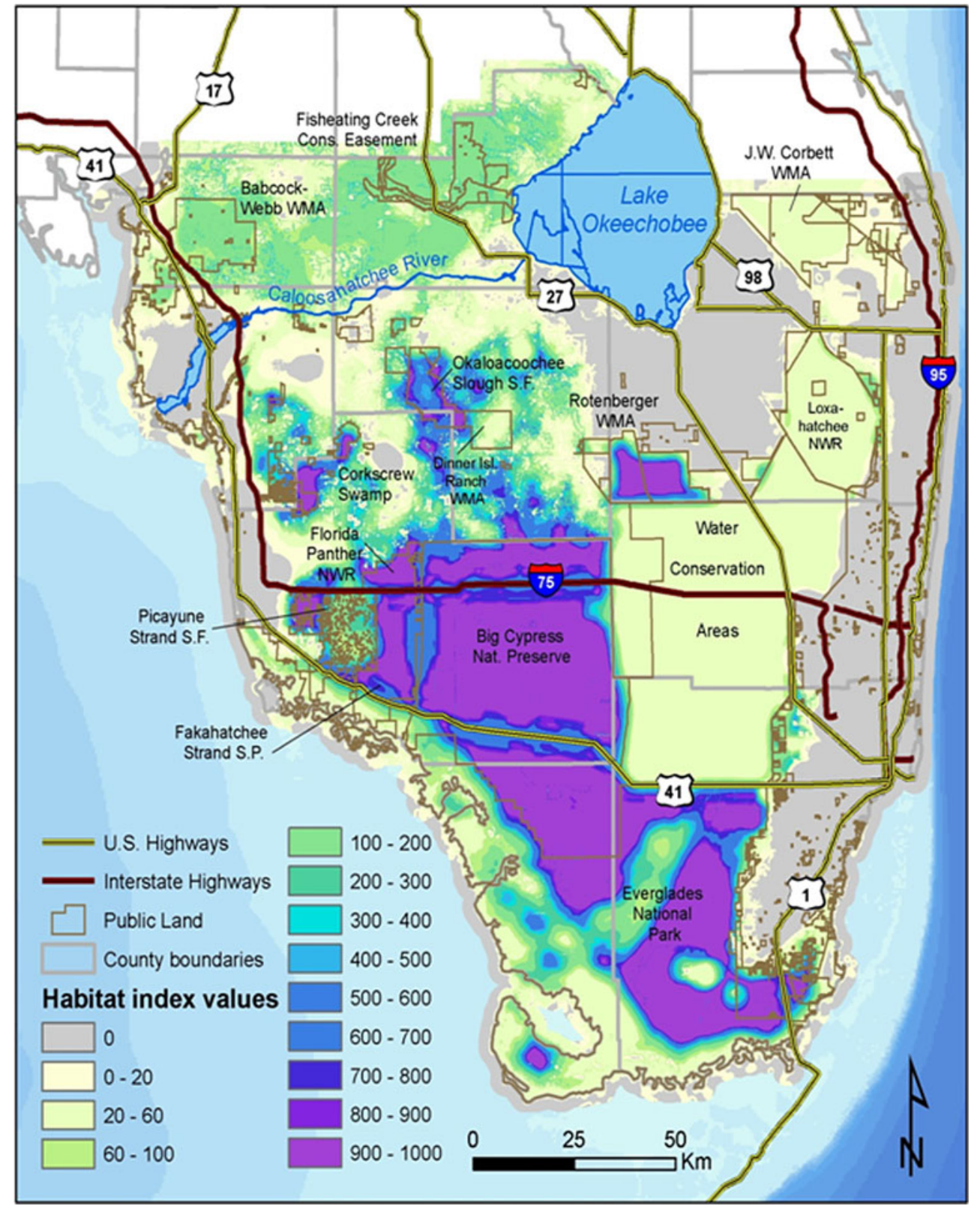




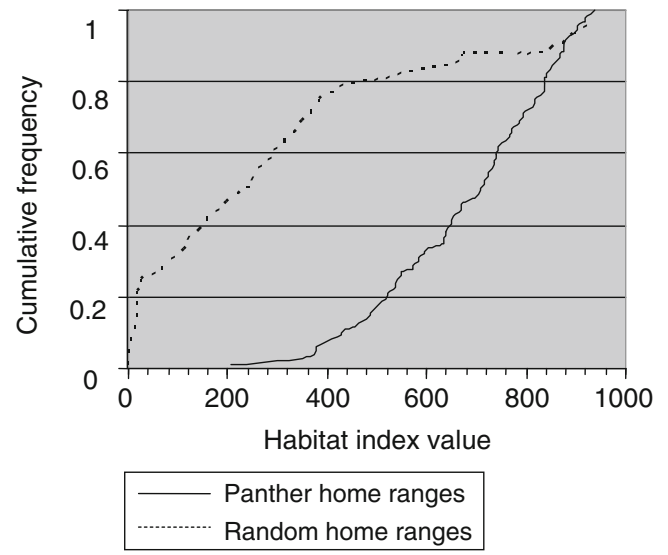

Fig. 4 Cumulative frequency distribution of mean habitat index values within Florida panther home ranges compared with mean habitat index values within randomly generated home ranges in south Florida

Additionally, the Boyce index had a positive correlation (mean $r_{\mathrm{s}}=0.975, P=0.005$, range $=0.783-0.975$ ) for the observed/expected ratio of home ranges with increasing panther habitat index values associated with the five bins. Thus, all validity tests suggested that habitat selection was occurring and the model was reliable.

The highest habitat index values occurred within current panther range, whereas the lowest values occurred in highly urbanized areas such as the city of Miami. Generally, high habitat index values occurred close to or within the core panther home range area, in areas with high percentage of natural land cover, in areas with low human population density and low road density, and in areas with little flooding. The stormwater treatment areas east of Big Cypress National Preserve received relatively low habitat index values because much of that area was permanently flooded.

\subsection{Florida Panther Habitat Estimator}

For the first simulation scenario, the original polygon included $1.372 \times 10^{6}$ habitat index units; the combined area of the polygon and the 3,280-m buffer area extending from its boundaries (default setting) was $8.842 \times 10^{6}$ habitat units (Fig. 5a). After we changed land cover to non-natural, there was a loss of $1,739 \times 10^{6}$ units $(19 \%)$ or 20.6 ha below the cutoff within the area of the polygon and the 3,280-m buffer (Fig. 5b). Increasing human population size by 5,000 residents resulted in a further loss of habitat units $\left(2.920 \times 10^{6}\right.$ habitat units, $33 \%, 23.1$ ha, 57 ac, Fig. 2, Fig. 5c).

In our second simulation scenario, land-cover conversion reduced the habitat index value from $3.984 \times 10^{8}$ to $3.412 \times$ $10^{8}$ units (a loss of $0.572 \times 10^{8}$ habitat units [14\%] or $13,179.7$ ha below the cutoff), primarily due to loss of connectivity with several important habitat patches to the north (Fig. 6a, b). Whereas the impact to habitat within the boundaries of the proposed development is clear, Fig. $6 \mathrm{a}, \mathrm{b}$ illustrates the farther-reaching impacts on the landscape that occurred based on the loss of connectivity.

\section{Discussion}

Pumas are one of the most widely distributed wild mammals in the western hemisphere and do not require a specific habitat structure or ecosystem type for survival. However, like other large carnivores, pumas exhibit characteristics (i.e., large home ranges, low densities, persecution by humans) that make them vulnerable to localized extinction due to habitat loss and fragmentation [9]. The best evidence for this is that Florida panthers persist today only in that portion of the southeastern US where human densities are lowest, vehicular access is most restricted, and habitat is most contiguous, despite prey densities that are less than optimal. Even at the more localized extent of our study, those factors heavily influenced our landscape model: Areas with a high percentage of natural habitat (forests, grasslands, shrublands, cypress swamps), low percent semi-natural (bare soil, pasture, sugar cane, exotic species), and with fewer roads were indicative of quality panther habitat. All tests indicated model predictions were reliable, a critical criterion if land managers are to use the model for decision support.

Simulation models allow managers and stakeholders involved in landscape planning to compare the outcomes of diverse scenarios. Our Florida Panther Habitat Estimator provides an objective and comprehensive comparison of habitat management alternatives by simultaneously incorporating multiple factors and their interactions that influence panther habitat. Habitat units can be totaled and directly compared among different land management alternatives, and the amount of panther habitat gained or lost can be determined based on the cutoff value. This provides more realistic predictions of habitat change than could be obtained by evaluating changes in a single variable, such as land use or human density. Additionally, the estimator quantifies not only how land-use changes could affect the land parcel but how such changes could affect the surrounding area beyond the boundaries of the parcel. Although our model effectively estimates the negative impacts to isolated land parcels when habitat corridors are disrupted, the model can also be used to assess the potential effects of corridor restoration.

There are some limitations to using a data-based tool to simulate habitat change. Our model is based on the assumption that the panther home ranges are distributed optimally within the landscape, and the panthers we chose for analysis were typical of the overall panther population. Also, Mahalanobis distance is prone to classification error if the model is applied to conditions that substantially differ from those 


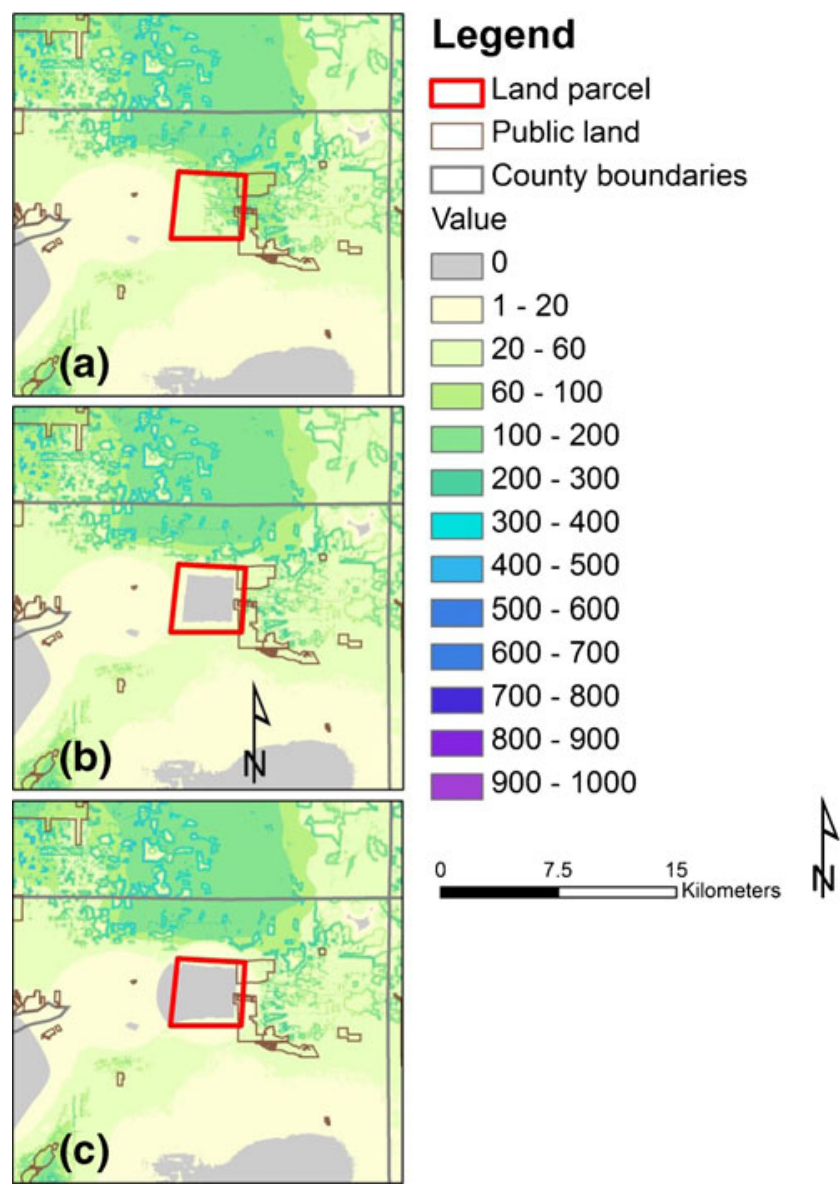

Fig. 5 Map output from the Florida Panther Habitat Estimator to quantify the impact of land-use changes on Florida panther habitat in south Florida. a Current panther habitat value of a hypothetical site (red boundary line; $18.2-\mathrm{km}^{2}$ ) in which future land-use changes may occur $\left(1.372 \times 10^{6}\right.$ habitat units within the polygon boundary). b Simulation of the potential change in panther habitat values due to a hypothetical conversion to non-natural land cover of the site but no additional residents (loss of 20.6 ha of habitat within the polygon and the 3,280-m buffer). c Results of the same simulation, but with the addition of 5,000 residents (loss of 23.1 ha of habitat within the polygon and the 3,280-m buffer)

used to develop the original model [33]. The data from which we developed the model were collected in the same general area where we applied the model. As time elapses and new spatial data become available (e.g., 2010 U.S. Census Bureau roads and population data), the landscape variables used to develop the habitat model can be updated. The statistical model (i.e., mean vectors and covariance matrices) should not have to be re-parameterized unless the landscape within the study area dramatically changes.

In most instances, the 3,280-m default buffer used in the Florida Panther Habitat Estimator is sufficient to capture all changes in habitat units. However, habitat units can change in areas beyond the default setting if changes in natural land cover result in isolation of or connection to distant habitat patches as measured with the cost-distance variable. Thus, a larger analysis area should be considered when a land-use change is in a location that could create or eliminate a connection to isolated habitat. We recommend estimating the change in habitat units with the default buffer and gradually increasing the study area size (i.e., buffer distance) until the result is consistent among simulation runs. In most cases, that can be accomplished with one buffer distance expansion run to confirm that the tally of habitat units is consistent. Regardless, this process should ensure that all changes in the habitat units are included without unnecessarily increasing computing time. We note that the habitat connectivity component of the model is based on least-cost path connections of pixels classified as natural habitat, with a minimum of two shared pixel edges representing connectivity. Thus, users should be aware that some corridors

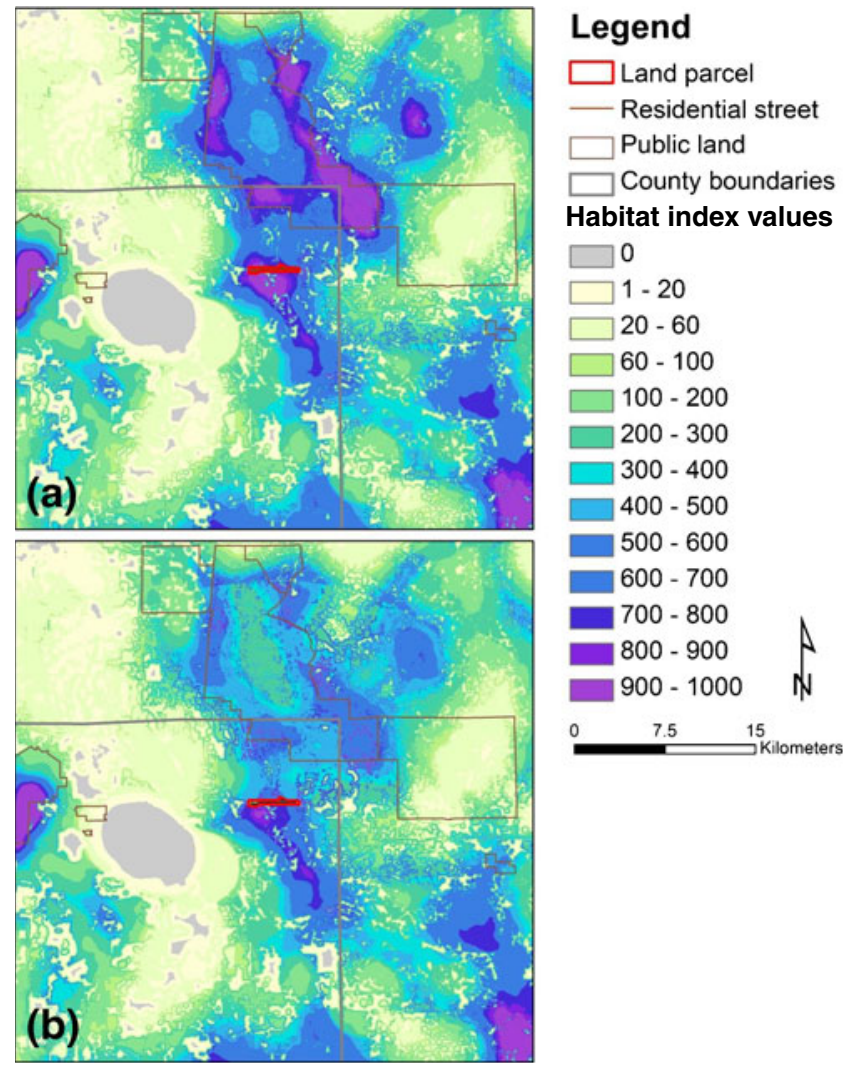

Fig. 6 Map output from the Florida Panther Habitat Estimator to quantify the impact of land use changes on Florida panther habitat in south Florida. a Current panther habitat value of a land parcel for which a hypothetical development (red boundary line; 169 ha) is proposed $\left(3.984 \times 10^{8}\right.$ habitat units). b Simulation of the potential change in panther habitat values for that parcel due to conversion of natural to non-natural habitat and the addition of roads and 240 residents. The number of habitat units after urban development is completed is $3.4124 \times 10^{8}$, a loss of $0.572 \times 10^{8}$ units (loss of $13,179.7$ ha of habitat within the polygon and the $18-\mathrm{km}$ buffer) 
identified by the model may only represent tenuous connections among natural habitat areas.

The habitat model we used as the basis for this habitat estimator is specific to the study area (south Florida) and the species (Florida panther). Because the programming code that underlies this habitat estimator can be easily modified, it could be adapted to any species for which suitable presence data are available to facilitate an objective, transparent process for evaluating habitat. Finally, we suggest that the predictions of the model should be evaluated over time. Presence-absence data could be used to determine if areas are used or avoided as predicted by the model after habitat changes occur.

Acknowledgment This study was funded by the US Fish and Wildlife Service and the US Geological Survey. We thank the Florida Fish and Wildlife Conservation Commission and the National Park Service for providing telemetry data. We thank Chris Belden of the US Fish and Wildlife Service for his help and support throughout the study. We also thank Jean Freeney of US Geological Survey, National Biological Information Infrastructure, for her assistance. We thank Chris Belden, Cindy Schultz, and Brad Rieck of the US Fish and Wildlife Service; Darrell Land of the Florida Fish and Wildlife Conservation Commission; and a number of anonymous reviewers of our final report for providing helpful suggestions and comments on the habitat model. The use of trade names is for the information and convenience of the reader and does not constitute official endorsement or approval by the University of Tennessee or the US Geological Survey of any product to the exclusion of others that may be suitable. For further information on the Florida Panther Habitat Estimator, users should contact USFWS, 1339 20th Street, Vero Beach, Florida 32960.

\section{References}

1. Adriaensen, F., Chardon, J. P., De Blust, G., Swinnen, E., Villalba, S., Gulinck, H., et al. (2003). The application of 'least-cost' modelling as a functional landscape model. Landscape and Urban Planning, 64, 233-247.

2. Buehler, D. A., Welton, M. J., \& Beachy, T. J. (2006). Predicting cerulean warbler habitat use in the Cumberland Mountains of Tennessee. Journal of Wildlife Management, 70, 1763-1769.

3. Boyce, M. S., Vernier, P. R., Nielsen, S. E., \& Schmiegelow, F. K. A. (2002). Evaluating resource selection functions. Ecological Modelling, 157, 281-300.

4. Browning, D. M., Beaupre, S. J., \& Duncan, L. (2005). Using partitioned Mahalanobis $D^{2}$ to formulate a GIS-based model of timber rattlesnake hibernacula. Journal of Wildlife Management, 69, 33-44

5. Clark, J. D., Dunn, J. E., \& Smith, K. G. (1993). A multivariate model of female black bear habitat use for a geographic information system. Journal of Wildlife Management, 57, 519-526.

6. Comiskey, E. J., Bass, O. L., Jr., Gross, L. J., McBride, R. T., Salinas, R. (2002). Panthers and forests in South Florida: An ecological perspective. Conservation Ecology, 6:18. <http:// www.consecol.org/vol6/iss1/art18>. Accessed 1 August 2002.

7. Corsi, F., Dupré, E., \& Boitani, L. (1999). A large-scale model of wolf distribution in Italy for conservation planning. Conservation Biology, 13, 150-159.

8. Cowardin, L. M., Carter, V., Golet, F. C., \& LaRoe, E. T. (1979). Classification of wetlands and deepwater habitats of the United States. Washington: U.S. Fish and Wildlife Service.
9. Crooks, K. R. (2002). Relative sensitivities of mammalian carnivores to habitat fragmentation. Conservation Biology, 16, 488-502.

10. Davis Jr., J. H. (1943). The natural features of southern Florida, especially the vegetation and the Everglades. Florida Geological Survey Bulletin, 25. Tallahassee, Florida, USA.

11. Dickson, B. G., Jenness, J. S., \& Beier, P. (2005). Influence of vegetation, topography, and roads on cougar movement in southern California. Journal of Wildlife Management, 69, 264276.

12. ESRI. (2006). ArcGIS desktop help. Redlands: ESRI.

13. Farber, O., \& Kadmon, R. (2003). Assessment of alternative approaches for bioclimatic modeling with special emphasis on the Mahalanobis distance. Ecological Modelling, 160, 115130.

14. Fleming, M. (1994). Distribution, abundance, and demography of white-tailed deer in the Everglades. In D. Jordan (Ed.), Proceedings of the Florida Panther Conference (pp. 494-503). Fort Myers: U.S. Fish and Wildlife Service.

15. Florida Fish and Wildlife Conservation Commission. (2003). Florida vegetation and land cover. http://myfwc.com/oes/habitat_sec/ gis/fl_veg03.htm. Accessed 12 July 2005.

16. Florida Geographic Data Library. (2005). Public lands. <http:// www.geoplan.ufl.edu/education.html $>$. Accessed 14 February 2006.

17. Foster, M. L., \& Humphrey, S. R. (1995). Use of highway underpasses by Florida panthers and other wildlife. Wildlife Society Bulletin, 23, 95-100.

18. Fritts, S. H., \& Carbyn, L. N. (2006). Population viability, nature reserves, and the outlook for wolf conservation in North America. Restoration Ecology, 3, 26-38.

19. Frontier, S. (1976). Étude de la décroissance des valeurs propres dans une analyse en composantes principales: Comparaison avec le modèle du bâton brisé. Journal of Experimental Marine Biology and Ecology, 25, 67-75.

20. Griffin, S. C., Taper, M. L., Hoffman, R., \& Mills, L. S. (2010). Ranking Mahalanobis distance models for predictions of occupancy from presence-only data. Journal of Wildlife Management, 74, $1112-1121$.

21. Gu, W., \& Swihart, R. K. (2004). Absence or undetected? Effects of non-detection of species occurrence on wildlife-habitat models. Biological Conservation, 116, 195-203.

22. Hirzel, A. H., Le Lay, G., Helfer, V., Randin, C., \& Guisan, A. (2006). Evaluating the ability of habitat suitability models to predict species presences. Ecological Modelling, 199, 142152.

23. Hoctor, T. S., Carr, M. H., \& Zwick, P. D. (2000). Identifying a linked reserve system using a regional landscape approach: The Florida ecological network. Conservation Biology, 14, 984-1000.

24. Hooge, P. N., \& Eichenlaub, B. (1997). Animal movement extension to ArcView. Version 2.04 beta. Alaska Biological Science Center, U.S. Geological Survey, Anchorage, Alaska, USA.

25. Horne, J. S., \& Garton, E. O. (2006). Likelihood cross-validation versus least squares cross-validation for choosing the smoothing parameter of kernel home-range analysis. Journal of Wildlife Management, 70, 641-648.

26. Jackson, D. A. (1993). Stopping rules in principal components analysis: A comparison of heuristical and statistical approaches. Ecology, 74, 2204-2214.

27. Jackson, J. E. (1991). A user's guide to principal components. New York: Wiley-Interscience: JohnWiley and Sons.

28. Janis, M. W., \& Clark, J. D. (2002). Responses of Florida panthers to recreational deer and hog hunting. Journal of Wildlife Management, 66, 839-848. 
29. Katnik, D. D., \& Wielgus, R. B. (2005). Landscape proportions versus Monte Carlo simulated home ranges for estimating habitat availability. Journal of Wildlife Management, 69, 20-32.

30. Kauhala, K., \& Tiilikainen, T. (2002). Radio location error and the estimates of home-range size, movements, and habitat use: A simple field test. Annales Zoologici Fennici, 39, 317-324.

31. Kautz, R., Kawula, R., Hoctor, T., Comiskey, J., Jansen, D., Jennings, D., et al. (2006). How much is enough? Landscape-scale conservation for the Florida panther. Biological Conservation, 130, 118-133.

32. Knick, S. T., \& Dyer, D. L. (1997). Distribution of black-tailed jackrabbit habitat determined by GIS in southwestern Idaho. Journal of Wildlife Management, 61, 75-85.

33. Knick, S. T., \& Rotenberry, J. T. (1998). Limitations to mapping habitat use areas in changing landscapes using the Mahalanobis distance statistic. Journal of Agricultural, Biological, and Environmental Statistics, 3, 311-322.

34. McGarigal K. \& Marks B. J. (1995). FRAGSTATS: Spatial pattern analysis program for quantifying landscape structure. USDA Forest Service General Technical Report PNW-351.

35. Morrison, M. L., Marcot, B. G., \& Mannan, R. W. (1992). Wildlife-habitat relationships: Concepts and applications. Madison: University of Wisconsin Press.

36. Moser, B. W., \& Garton, E. O. (2007). Effects of telemetry location error on space-use estimates using a fixed-kernel density estimator. Journal of Wildlife Management, 71, 2421-2426.

37. Peterson, A. T., Stockwell, D. R. B., \& Kluza, D. A. (2002). Distributional prediction based on ecological niche modelling of primary occurrence data. In J. M. Scott, P. J. Heglund, M. L. Morrison, J. B. Haufler, M. G. Raphael, W. A. Wall, \& F. B.
Samson (Eds.), Predicting species occurrences: Issues of accuracy and scale (pp. 617-623). Washington: Island Press.

38. Rao, C. R. (1952). Advanced statistical methods in biometric research. New York: John Wiley and Sons.

39. Seaman, D. E., \& Powell, R. A. (1996). An evaluation of the accuracy of kernel density estimators for home range analysis. Ecology, 77, 2075-2085.

40. Seaman, D. E., Millspaugh, J. J., Kernohan, B. J., Brundige, G. C., Raedeke, K. J., \& Gitzen, R. A. (1999). Effects of sample size on kernel home range estimates. Journal of Wildlife Management, 63, 739-747.

41. Thatcher, C. A., van Manen, F. T., \& Clark, J. D. (2009). A habitat assessment for Florida panther population expansion into central Florida. Journal of Mammalogy, 90, 918-925.

42. Thompson, L. M., van Manen, F. T., Schlarbaum, S. E., \& DePoy, M. (2006). A spatial modeling approach to identify potential butternut restoration sites in Mammoth Cave National Park. Restoration Ecology, 14, 289-296.

43. U.S. Department of Agriculture Natural Resources Conservation Service. (2006). http://www.ncgc.nrcs.usda.gov/products/datasets/ climate/data/index.html. Accessed 2 May 2006.

44. U.S. Fish and Wildlife Service. (2006). Third revision Florida panther recovery plan, Atlanta, Georgia, USA.

45. Worton, B. J. (1989). Kernel methods for estimating the utilization distribution in home-range studies. Ecology, 70, $165-168$.

46. Worton, B. J. (1995). Using Monte Carlo simulation to evaluate kernel-based home range estimators. Journal of Wildlife Management, 59, 794-800. 